\title{
Alen Širca
}

\section{Um kot zvezda pri Evagriju Pontskem in $\mathrm{v}$ sirski mistiki}

Znano je, da so helenistični filozofi pogosto razpravljali o tem, čemur bi danes precizneje rekli astronomija, namreč o ustroju in pomenu nebesnih teles. $\mathrm{O}$ teh so imeli tedaj - gledano kajpak $\mathrm{z}$ naše, moderne perspektive - precej bizarna mnenja. Vse klasične filozofske šole - razen epikurejcev - so se strinjale glede tega, da so nebesna telesa živa bitja, razhajali so se samo glede tega, kakšen naj bi bil način tega življenja, ali imajo dušo ali ne ter ali so celo nekakšna božanstva itn.

$\mathrm{V}$ antično krščanstvo je helenistično astralno filozofijo in teologijo zanesel Origen (185-254). Eno izmed njegovih najbolj kontroverznih stališč je bilo pritrditev stari pitagorejsko-platonski ideji o tem, da obstaja posebna zveza med dušo zvezde (astralno dušo) in človeško dušo, ter njeni vključitvi v krščansko teologijo. Tako je na primer pavlinsko tezo o duhovnem vstajenju skušal uskladiti s spekulacijami o vodniški vlogi zvezd v zagrobni usodi človeške duše. ${ }^{1}$

Seveda pa Origen svoje astralnoteološke spekulacije ni jemal preresno, nanje je gledal kot na neke hipoteze, o katerih se in statu via ni mogoče dokopati do dokončnega odgovora. $\mathrm{V}$ spisu $O$ počelih o védenju o zvezdah pravi takole:

Ko bodo torej sveti prispeli v nebeške kraje, tedaj bodo sprevideli posamezne smisle (ratio) zvezd in ugotovili, ali so živa bitja oziroma, kaj sploh so. A spoznali bodo še druge smisle Božjih del, ki jim jih bo on sam razodel. Vzroke vseh stvari in moč svojega stvarjenja jim bo namreč pokazal že kot sinovom in jih bo poučil, zakaj je neka zvezda postavljena na tisto mesto neba in od druge zvezde ločena s takšno vmesno razdaljo. In na primer, kakšne bi bile posledice, če bi bila bliže, kaj bi se zgodilo, če bi bila dlje; ali kako vesolje ne bi bilo več podobno sebi, temveč bi se vse spremenilo v neko drugo obliko, če bi bila ona zvezda večja od druge.

(O Počelih, 189)

1 O tem gl. zlasti Scott, Origen and the Life of the Stars, 113-64. Prim. tudi. Monaci Castagno, "Astri«, 40-43. 
Zanimivo je, da je pozneje Origenovi astralni teologiji oziroma vsaj njegovemu mnenju, da so zvezde živa in (raz)umska bitja, sledil Ambrozij Milanski, medtem ko sta na Vzhodu tako zagrizena origenista, kot sta bila Bazilij Cezarejski (imenovan tudi Véliki) in Didim Slepi, to mnenje ognjevito izpodbijala. Nekoliko drugače pa je še z enim Origenovim »učencem«, Evagrijem Pontskim. Kot bomo videli, je ta poznoantični krščanski diskurz o zvezdah docela obrnil na glavo.

\section{EVAGRIJ PONTSKI IN MISTIČNA "ASTROLOGIJA"}

Evagrij Pontski (345-399), ki ga je odkrilo šele 20. stoletje, velja danes za enega izmed največjih filozofskih glav med puščavskimi očeti, za pravega »filozofa $\mathrm{v}$ puščavi«, in tudi za »najpomembnejšega puščavskega očeta 4. stoletja «. ${ }^{2}$ Rodil se je v Ibori (Mala Azija). Bil je tesno povezan s t. i. Vélikimi Kapadočani, cerkvenimi očeti, ki so bili najzaslužnejši za izdelavo dogme o Sveti Trojici, zlasti z Bazilijem Cezarejskim in Gregorjem iz Nazianza. Po zapletu v Carigradu, kjer se je zaljubil v ženo visokega uradnika, je zbežal v Jeruzalem. Kmalu se je pomenišil in se priključil egiptovskemu meniškemu gibanju. Nazadnje je s svojimi somišljeniki bival v Keliji. Na podlagi svoje puščavniške izkušnje in izkušnje svojih učiteljev (zlasti Makarija Vélikega in Makarija Aleksandrijskega) je opravil prvo teološko sintezo meniške duhovnosti. Intelektualno je bil pod močnim vplivom aleksandrijske katehetske šole (Klement Aleksandrijski, Origen). Čeprav ga je (kalcedonska) latinsko-grška Cerkev na 2. carigrajskem koncilu leta 553 posthumno obsodila kot heretika, pa nekatere nekalcedonske Cerkve te obsodbe niso sprejele. Armenska Cerkev ga, recimo, še danes časti kot svetnika.

Evagrij je tudi eden izmed očetov krščanske mistike (poleg Klementa Aleksandrijskega, Origena in Gregorja iz Nise). Strokovnjaki njegovo mistiko navadno opredeljujejo s pojmom mistike luči (mystique de la lumière). ${ }^{3} \mathrm{Ta}$ je pomembno vplivala na nadaljnji razvoj krščanske duhovnosti. Na Zahod jo je v nekoliko »omehčani « obliki ponesel Janez Kasijan, njene sestavine pa so bile prisotne zlasti v srednjeveški benediktinski mistiki. Tudi na grškem Vzhodu je kljub temu, da je bilo precej njegovih del uničenih, pod imeni drugih, manj kontroverznih piscev odločilno zaznamoval bizantinsko mistiko od Maksima Spoznavalca do hezihastičnih mojstrov, kot sta bila Gregor Sinajski in Gregor Palamas. Nedvomno pa je Evagrij najbolj vplival na krščanski Vzhod v pravem pomenu besede, se pravi na nekalcedonske Cerkve, še zlasti pa na semitsko sirsko krščanstvo. Vznika nestorijanske mistike 7. in 8. stoletja si brez Evagrija

2 Linge, $»$ Leading the Life of Angels«, 537.

3 Wilhelm Bousset, Apophthegmata, 92, ga je celo oklical za »začetnika in iznajditelja prave krščanske mistike«. Hans Urs von Balthasar pa pravi, da »ni samo malone neomejeni gospodar celotne sirske in bizantinske mistike, ampak je odločilno vplival tudi na zahodno mistiko in estetiko« (»Metaphysik und Mystik des Evagrius Ponticus«, 31). Owen Chadwick, John Cassian, 82 , ga podobno imenuje za »očeta naše duhovne književnosti«. 
sploh ne moremo zamisliti. Vendar o tem več pozneje.

Brez pretiravanja lahko trdimo, da je bil Evagrijev vpliv na poznejše krščanstvo izjemen. Njegovi spisi so bili prevedeni malone v vse »klasične« cerkvene jezike: ${ }^{4}$ poleg Latincev, Grkov in Sircev so njegova dela prevajali in komentirali tudi Armenci (ti so jih prevajali bodisi neposredno iz grščine bodisi posredno iz sirščine). Razen tega pa na nekatera njegova dela naletimo tudi v drugih krščanskih orientalskih jezikih: $v$ arabščini, etiopščini, gruzijščini in celo sogdijščini (iranskem jeziku ob svilni poti), kar pomeni, da so ga svoj čas brali tudi globoko v osrednji Aziji. Primerljiv duhovnozgodovinski doseg iz tega časa imajo samo še Apophthegmata Patrum.

Preden se lotimo analize Evagrijevega zvezdoslovja, je treba opozoriti tudi na njegov slog. Evagrijeva grščina je literarno precej »čista ${ }^{5}$ in dosega raven prej omenjenih vélikih Kapadočanov. Čeprav nemara zaradi specifičnega načina pisanja, ki ga je Evagrij gojil, to ni tako vidno. Evagrijev slog je izrazito gnomičen. $\mathrm{V}$ tem pogledu je nanj na eni strani prav gotovo vplivala grška gnomična literatura (Mark Avrelij, Porfirij), na drugi strani pa biblična sapiencialna (modrostna) književnost. Evagrij je svojo misel najraje izoblikoval v kratkih stavkih, imenovanih »poglavja« (kephálaia), ki - vsaj na prvi pogled - med seboj niso povezani. V tem smislu je pomenljiv naslov njegovega poglavitnega mistično-spekulativnega dela: Gnostična poglavja (Kephálaia gnostiká, izvirnik je razen fragmentov izgubljen, delo je v celoti ohranjeno samo v sirščini, Reše d-idata). Zdi se, da je bil Evagrij prvi, ki je ta kratka "poglavja" združil v »centurije«, tj. stotice. To so posnemali zlasti bizantinski avtorji (na primer Maksim Spoznavalec).

Zdaj pa k zvezdam. Čeprav je Evagrij v marsičem Origenov učenec, pa je njegova v misel tudi izvirna. Origenu sledi v tem, da imajo zvezde - v dobesednem kozmološkem pomenu - podobno vlogo kot angeli in da so živa, racionalna bitja $\mathrm{z}$ dušo.

V Gnostičnih poglavjih Evagrij docela v duhu Origena pravi, da se zvezde razlikujejo druga od druge glede svojega veličastva in da imajo svoje poslanstvo od Boga:

Zvezde se razlikujejo druga od druge glede veličastva in ne glede telesa. Njihova vzvišenost, liki in oddaljenost od druga druge ter njihov tek so različni. To, da so nekatere $\mathrm{v}$ dosegu zemljine sence, nekatere zunaj njega in nekatere na njegovi meji, kaže na njihove redove in gospostva, ki jih jim je zaupal Bog. (KG 3.37)

4 Nekaj Evagrijevih spisov oziroma odlomkov iz njih je v slovenščino prevedel Gorazd Kocijančič: »Gnostik ali tistemu, ki je bil vreden spoznanja«, Nova revija 115 (1991): 1393-1403; Praktik, Nova revija 129/130 (1993): 147-64; "153 poglavij o molitvi«, v: Grški očetje o molitvi, Celje: Mohorjeva družba, 1993, 207-23. Pri založbi KUD Logos je v pripravi prevod Evagrijevih zbranih del.

5 Prim. Guillaumont, Évagre le Pontique, Traité pratique, 433. 
Podobno kot Origen skuša svojo astralno teologijo uskladiti s Svetim pismom:

Za naše odrešenje si ne prizadevajo samo angeli, temveč tudi zvezde, če so na dan Baraka z neba bojevale vojno s Sisarom. (KG 6.88) ${ }^{6}$

Evagrijeva izvirna »astrologija« se kaže zlasti v mističnemu pojmovanju zvezde. Evagrij duhovno življenje razdeli na tri stopnje (takšna tripartitna je nedvomno stoiška dediščina): na praktiko (praktiké), fiziko (physiké) in teologijo (theología). Pogosto pa uporablja tudi preprostejšo dvodelno delitev na praktiko in gnostiko (gnostiké). Tu nas bo zanimala samo zadnja stopnja, teologija, ki pomeni motrenje Boga in vstop v mistiko v strogem pomenu besede. Theología se godi prek t. i. čiste molitve, ki je - če lahko tako rečemo - hipernoematična, osvobojena vsakršne podobe in predstave oziroma uzrtja (nóema), povrhu pa se tudi ne sme ujeti v predmetnost umskega zrenja, kontemplacije (theórema), saj je treba doseči pogled oziroma motrenje onstran vsakršne forme. $V$ takšen stanju čiste molitve um lahko zre samega sebe, kakršen je, in uvidi, da je poln svetlobe oziroma da postane kot luč ali celo zvezda. Tako v Evagrijevem spisu O mislih (Perì logismôn) beremo:

Tedaj se bo v tebi vzdignila brezstrastnost [apátheia] srca in v molitvi boš uzrl svoj um v obliki zvezde [noûs asteroeidés]. (Sur les pensées, 298)

Podoba zvezde meri na nekakšno eksplozijo luči, sijanje izjemno močne luči. Zato besedo asteroeidés ponekod zamenja splošnejši izraz photoeidés: »Um, ki je slečen strasti, postane ves kot luč [sir. ajk nuhra, gr. retroverzija po Frankenbergu je photoeidés], saj je razsvetljen prek motrenja bitnosti« (KG 5.15).

V Motrenjih (Skemmata), 25 pa beremo: »Božji kraj je torej za smisel dovzetna duša, Njegovo prebivališče pa je lučnoobličen [photoeidés] um, ki je zavrnil svetne užitke in se je naučil opazovati smisle [lógoi] zemlje. « ${ }^{7}$

Najboljši komentar k tem težavnim odlomkov je zgodba ali morda celo legenda (vsaj če jo razumemo v izvornemu pomenu kot »tisto-kar-naj-se-bere«). Rufin v svojem »travelogu « Zgodovina menihov v Egiptu pripoveduje, da je Evagrij na vsak način hotel vedeti, ali luč, ki jo um v čisti molitvi zre, prihaja od njega samega ali od Boga. ${ }^{8}$ Evagrija je to vprašanje tako pestilo, da se je namenil $\mathrm{k}$ slovitem vidcu Janezu iz Likopolisa, ki je med drugim napovedal,

6 Prim. Sod 5:20.

7 Izvirnik Muyldermans, »Evagriana«, 37-68. Slov. prev. Gorazd Kocijančič, »Motrenja« (neobjavljeno). Podobno beremo tudi v t. i. Poglavjih Evagrijevih učencev: »Ko um v praktiki napreduje, so njegova uzrtja čutnega [noémata tôn aisthetôn] lahka. Ko napreduje v znanosti, ima raznovrstna zrenja [theorémata]. Ko pa napreduje v molitvi, zre svojo lastno luč bolj sijočo in žarečo." (Chapitres des disciples d'Évagre, 174).

8 Pravzaprav avtor tega spisa bržkone ni Rufin, zato danes pisca tega dela označujemo s PsevdoRufinom. Svoje romanje k Janezu iz Likopolisa popisuje Evagrij sam v Antiretiku (Ugovarjalcu) 6. 
da bo Teodozij Véliki premagal poganskega Evgenija, vladarja Zahodnega cesarstva, v bitki pri Frigidu (bržkone v bližini današnje Vipave) leta 394. Evagrij se je podal na dolgo in nevarno pot v Likopolis (danes Asjut). To mesto je bilo kakih štiristo kilometrov od Kaira oziroma Kelije, kjer je bila Evagrijeva celica, pot pa je trajala kakih osemnajst dni. Vendar mu videc Janez ni dal enostavnega oziroma enoznačnega odgovora. Pravzaprav se zdi, da se je odgovoru kratko malo ognil in tako posredno nakazal, da je samo vprašanje napačno postavljeno: „Ni v moči človeka, da bi to lahko pojasnil, vendar um med molitvijo ne more biti ožarjen brez Božje milosti in ne da bi bil osvobojen številnih in grenkih sovražnikov, ki si prizadevajo za njegov padec. «9

Ta odgovor je Evagrija spodbudil k temu, da se je sam dokopal do "pravega « odgovora. Spoznal je, da v resnici ne gre za ali - ali, se pravi, da zrenja Svete Trojice in samozrenja uma pravzaprav niti ni treba ločevati. Pri tem se je oprl na eksegezo Eksodusa 24.10. Očitno je imel pred sabo Septuaginto, ki za razliko od masoretskega besedila (»videli so Izraelovega Boga «) to mesto prevaja takole: »Videli so kraj, na katerem je bil Izraelov Bog «. ${ }^{10}$ Aleksandrinski prevajalci so se očitno bali, da bi z dobesednim prevodom »blasfemično« implicirali, da so Izraelci zrli Boga neposredno. Zato so vstavili besedico »kraj«, ta pa je ustreznica hebrejskega maqom, ki je eno izmed legitimnih Božjih imen. V spisu O mislih Evagrij, razlagajoč teofanijo iz Eksodusa, lucidno pravi:

Ko bo um slekel starega človeka in oblekel tistega, ki se rodi iz milosti, bo med molitvijo videl svoje lastno stanje [katástasis], podobno safirju in barvi neba. Temu stanju Sveto pismo pravi Božji kraj, ki so ga stari videli na sinajski gori (Sur les pensées, 286 in 288).

Božji maqom je, še natančneje rečeno, luč brez oblike, ki je medij samozrenja preobraženega uma: "Ko um biva v praktiki, se nahaja v uzrtjih tega sveta; ko biva v spoznanju, prebiva $\mathrm{v}$ motrenju, in ko se znajde v molitvi, je v brezobličnem, ki se imenuje 'Božji kraj. "'11 Torej svetloba brez oblike prihaja od Boga, in samo v njej lahko um vidi tudi svojo lastno presojnost, svojo lastno svetlobo, ki je podobna safirnati barvi neba.

Motrenje Boga oziroma, natančneje, spoznanje Svete Trojice (gnôsis tês hagías Triádos), ki je edino bitnostno spoznanje (gnôsis ousiódes) je treba pri Evagriju, podobno kot pri Origenu, v zadnji instanci razumeti kot zedinjenje $\mathrm{z}$ lučjo Sv. Trojice oziroma kratko malo Boga.

9 To zgodbo povzemam po Guillaumont, Un philosophe au désert, 298-306. Prim. tudi isti, Aux origines du monachisme chretien, 136-47, in Harmless, Desert Christians, 345-71.

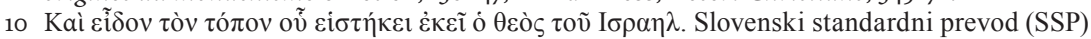
prevaja takole: »In videli so Izraelovega Boga; pod njegovimi nogami je bil nekakšen tlak iz safirja, tako čist kot samo nebo.«

11 Motrenja, 20. Prev. G. Kocijančič. 


\section{MISTIČNO ZVEZDOSLOVJE V SIRSKI MISTIKI}

Omenil sem že, da je Evagrijeva mistika še bolj kot v Bizancu zaživela med Sirci. Tu so se ohranila tudi tista dela, zvečine bolj spekulativnega značaja, ki so jih "pravoverni« Grki že zgodaj uničili. Evagrij je za Sirce kratko malo mistični teolog par exellence, oziroma, povedano s sirskim evagrijanskim izrazom, "največji med gnostiki« ${ }^{12}$ Utrinke Evagrijeve mistične "astrologije « zvečine opazimo samo pri nestorijancih, se pravi vzhodnosirskih kristjanih.

Omejili se bomo na dva poglavitna lika te mistike.

Eden izmed najpomembnejših vzhodnosirskih mistikov 8. stoletja je nedvomno Javsep Hazzaja oziroma, kot bi njegovo ime lahko poslovenili, Jožef Motrilec. ${ }^{13}$ Rodil se je na začetku 8 . stoletja v zoroastrski družini. Pri sedmih letih so ga ujeli in zasužnjili Arabci. Potem je prišel v roke nekemu krščanskem gospodu in postal kristjan. Po krstu je vstopil v samostan na severu Iraka. Pozneje je bil opat v več samostanih. Na sinodi leta 786 ga je skupaj z Janezom iz Daljate in Janezom iz Apameje izobčil Sirski patriarh Timotej I. Kljub temu gre za enega izmed najglobljih in najplodovitejših piscev vzhodnosirske Cerkve. Komentiral je dela Evagrija Pontskega, Izaije iz Sketisa in Dionizija Areopagita. Ohranilo se je le malo od njegovih številnih del, njegova mistična teologija pa je najbolje razvidna iz Pisma o treh stopnjah meniškega življenja. ${ }^{14}$ Tu gre za sintezo mistologije Evagrija Pontskega in Janeza iz Apameje (5. stoletje), ki prav tako spada med očete sirske mistike. Kontemplacija oziroma motrenje Boga pri njem kulminira $\mathrm{v}$ duhovnem pomešanju (sir. hbikuta) $\mathrm{z}$ lučjo Svete Trojice.

V Pismu o treh stopnjah naletimo samo na eno omembo zvezde, in sicer z ozirom na čistost in svetost; ti duhovni zadržanji sta za Jožefa "pečata, ki odsevata luč Svete Trojice in ki se prikažeta med molitvijo v podobi močno sijoče zvezde« (Lettre sur les trois étapes, 372 ).

Nekoliko več o mistični astrologiji tega sirskega evagrijevca izvemo iz pisem, ki jih najdemo na koncu zbirki pisem Janeza iz Daljate (o tem mistiku več pozneje). Robert Beulay je pokazal, da nekaj pisem iz te zbirke pripada Jožefu Motrilcu. ${ }^{15}$

V 48. pismu te zbirke pisem se nebesna telesa, zlasti sonce in zvezde, pojavljajo na firmamentu srca oziroma uma. Priča smo evagrijevski interiorizaciji in alegorizaciji. Tu sonce kajpak pomeni Boga, zvezde pa to, čemur Evagrij pravi logoí (sir. sukkale), (metafizične) »vzroke« oziroma, bolje, »smisle«. Na nižji duhovni stopnji, stopnji čistosti (sir. dakjuta), zvezde pomenijo smisle ustvarjenih resničnosti (sukle d-kjane da-brite). Ta stopnja čistosti ustreza

12 Nav. po. Guillaumont, Les „Képhalaia gnostica« d'Évagre le Pontique, 198.

13 Pregledno o njem Robert Beulay, "Joseph Hazzāyā«, v: Dictionaire de spiritualité, fasc. 57 (1974), stolp. 1344-1346, in Colless, The Wisdom of the Pearlers, 93-96.

14 Odlomek iz tega dela sem pred časom prevedel v slovenščino: gl. Jožef Motrilec (Javsep Hazzaja), „Pismo o treh stopnjah meniškega življenja«, Nova revija 27, št. 312-14 (2008): 155-57.

15 Gl. »Introduction«, v: Lettres, 296. 
Evagrijevemu konceptu drugega naravnega motrenja. ${ }^{16}$ Povrhu se zdi, da Jožef implicitno komentira Evagrijevo kriptično sentenco iz Gnostičnih poglavij (KG 3.84): »Vsako drugo naravno motrenje nosi znamenje zvezd; in zvezde so tisti, ki jim je bilo zaupano, da razsvetljujejo tiste, ki so v temi. $^{17}$

Na višji duhovni stopnji, stopnji t. i. "presojnosti« (sir. šapjuta) Jožef uporablja podobo zvezdnega neba skupaj s sončno svetlobo. In razlaga, da gre tu za motrenje Božjega veličastva (sonce), kakor to odseva v »smislih novega sveta« (zvezde). Novi svet tu pomeni zgolj duhovne resničnosti. Ti smisli so seveda $\mathrm{v}$ nasprotju s smisli ustvarjenih resničnosti že docela neizrekljivi. Za tem je samo še povsem presežna stopnja, ki jo ponazarja videnje sonca samega brez zvezd. Pri tem gre za motrenje Božje luči, ki zastre vsakršne lógoi, pa najsi bodo še tako vzvišeni. To motrenje je naposled samo drugo ime za zedinjenje človeškega uma $\mathrm{z}$ Bogom.

Čeprav v naslednjem, 49. pismu, ki je prav tako izpod peresa Jožefa Motrilca, naletimo na opis stanja, v katerem se menihu prikaže »oblak samo umu dostopnih zvezd « (anana d-kavkbe metidane) in s katerim potem hvali Boga - to na neki način podpira razlago, da so zvezde angeli ali vsaj njim podobna bitja - je to pismo prava »antifenomenologija« mistične izkušnje. Jožef namreč opozarja, da je vsako videnje, ki je naperjeno na neki (realni ali imaginarni) predmet, nevarno. Posebej opozarja, da so videnja predmetov sferičnih in zvezdastih oblik, mavrice, prestola, ognjenega vozu, ognjenih konjev itn. v resnici demonska. ${ }^{18}$ Mistično zrenje mora, nasprotno, biti vedno zrenje onkraj zrenja, popolnoma odvezano vsakršne objektivnosti.

Zrenje notranjega firmamenta duše, ki je onkraj likov in oblik, pa je po Jožefu »varno«, se pravi, da prihaja od Boga. Zato pravi:

Če pa včasih znotraj sebe uzreš nekaj takšnega, ki je kakor krogla ali kakor zvezda, se ne vznemirjaj, kajti tudi duša sama je je takšne oblike. Vsekakor pa se varuj reči, ki so pojavljajo od zunaj. (Lettres, 521)

Zvezda je naposled tako kot pri Evagriju »šifra« (paradoksna oblika brez oblike) za dušo samo. Duša je torej zvezdaste »oblike« oziroma, drugače rečeno, je

16 Stopnja gnostike za Evagrija pomeni vstop v »fizično « zrenje (theoría physiké), ki ima dve ravni: drugo naravno in prvo naravno zrenje. Drugo naravno zrenje ne pomeni, da gre za navadno (filozofsko) zrenje čutno zaznavnih in umu dostopnih resničnosti, ampak ima za svoj cilj duhovno zrenje "smislov« snovnega sveta, zrenje njegove umljivosti. Prvo naravno zrenje pa pomeni vstop v »angelsko življenje« (bíos angelikós), v katerem lahko um neposredno zre umljive resničnosti, kar pomeni, da gre že za nekakšno spoznavanje Boga, čeprav posredno. Gnostik tu še ne zre Božje narave, ampak njen odsev, njeno eksoterično luč. V Gnostičnih poglavjih je ta stopnja enaka kontemplaciji »smislov« previdnosti in (poslednje) sodbe, kar ima tako ontološko-kozmološko kot eshatološko razsežnost: to pomeni, da motri počela telesnega in netelesnega sveta, vrhovni smisel in smoter njihovega bivanja ter »smisle« glede odrešenja vseh za smisel dovzetnih bitij.

17 Podobno beremo tudi v KG 3.62: „Umu dostopne zvezde [kavkbe metidane] so bitnosti z razumom, ki jim je bilo zaupano, da razsvetljujejo tiste, ki so v temi«.

18 Videnje prestola morda implicira kritiko tedanje judovske mistike. 
prav tako brezoblična kot zvezda. Vendar je njeno brezoblično svetlobo mogoče motriti samo na ozadju še močnejše in prvotnejše svetlobe, ki jo daje sonce; to pa je v krščanski duhovnosti že od nekaj oznaka za Boga. Jožef Motrilec pride do podobnega uvida kot Evagrij: um lahko zre samega sebe le v Božji svetlobi; povedano še drugače: zrenje samega sebe in zrenje Boga je eno in isto zrenje, eno in iste spoznanje, zedinjenje človeškega uma, ne z Bogom kot takim ( $\mathrm{z}$ njegovo bitjo), ampak z njegovim izžarevanjem, svetlobo oziroma lučjo.

$\mathrm{Na}$ koncu si zelo na kratko oglejmo motiv zvezde še pri enem pomembnem sirskem mistiku, že omenjenemu Janezu iz Daljate.

Besedila, ki so se ohranila anonimno, zgolj pod imenom »sveti saba (sir. starec)«, so šele novejše raziskave pripisale Janezu iz Daljate, sicer znanem tudi pod imenom Janez Starec (Johannan Saba). Njegovo pravo ime je bilo zakrito zato, ker ga je vzhodnosirski patriarh Timotej I. obdolžil mesalijanske herezije. To pa ni moglo zadržati vpliva njegovega duhovnega nauka. Njegovi spisi, ki obsegajo homilije, pisma in izreke, so bili namreč na krščanskem Vzhodu nenavadno priljubljeni. Prevedli so jih tudi v arabščino in etiopščino ter nekaj malega (pod imenom Izaka iz Niniv) v grščino. Janez se je rodil v Nuhadri (Dohuku) na severu današnjega Iraka, kot puščavnik pa je živel v Daljati in potem na gori Qardu (al-Džudi). Na tej gori, na kateri naj bi po starem izročilu pristala Noetova barka, je tudi ustanovil samostan. Tako kot pozneje Frančiška Asiškega na Zahodu se ga je držal sloves, da se ga živali niso bale. ${ }^{19}$

Za Janeza iz Daljate je tako kot za večino krščanskih mistikov kraljevska pot na vrhove mističnega življenja ponižnost. V svojem 44. pismu enega izmed svojih bratov opominja takole:

Vedno se ogrinjaj, o moj brat, $\mathrm{v}$ ponižnost, saj bo tvojo dušo znova oblekla $\mathrm{v}$ Kristusa. Ponižnemu se razodene žareča zvezda lepote; vzdigne s v njegovem srcu in pri vsakem pokleku, ki ga naredi v molitvi, uzira njeno čudovito žarenje. (Lettres, 451 )

Janez je za razliko od Jožefa manj spekulativen in bolj bibličen. Ta navedek se očitno navdihuje po temle odlomku iz Drugega Petrovega pisma (2 Pet 1.19):

Tako je preroška beseda za nas postala še trdnejša in prav delate, da nanjo pazite kakor na svetilko, ki sveti na mračnem kraju, dokler ne zasije dan in ne vzide danica/jutranja zvezda [phosphóros] v vaših srcih. ${ }^{20}$

Za Janeza iz Daljate je v skladu s tem bibličnim odlomkov zvezda vedno Kristus. Podobno v neki (še neizdani) homiliji zakliče h Kristusu takole: »O

19 Prim. Colless, Wisdom of Pearlers, 96-96, in isti, »The Mysticism of John Saba«, 83-102.

20 Izvirnik vstavljam iz elektronske izdaje bibličnih besedil Bibleworks 9 (Nova zaveza je tu dostopna v Nestle-Alandovi izdaji). 
zvezda, ki se dvigaš v srcu in se razodevaš v duhu [b-havna] ... $\mathbb{1}^{21}$

Poleg tega se zdi, da je bolj kot Evagrij na Janeza vplival Makarij Egiptovski - prav tako velika avtoriteta vzhodnokrščanske duhovnosti. ${ }^{22}$

Na koncu se mi postavlja intrigantno vprašanje, ali gre tu samo za preprosto alegorizacijo $\mathrm{v}$ temelju astronomske entitete, namreč zvezde (gr. astér, sir. $k a v k b a)$, katere vloga je nekakšna vizualna didaktika religiozne izkušnje, ali pa še za "nekaj več«. Odgovor je povsem odvisen od perspektive. Gledano z »objektivnega«, zunanjega znanstveniškega stališča gre za učinkovit in morda tudi (literarno) zanimiv eksegetski postopek, $\mathrm{s}$ »subjektivnega « stališča mistične izkušnje same pa se stvari bržkone vrtoglavo zapletejo. Najprej se zamaje sama objektivistična distinkcija med »zunaj« in »znotraj«, med zunanjim tvarnim in notranjim duševnim svetom. In če bi v tej smeri tipali naprej, bi bili nemara naposled prisiljeni soočiti se s paradoksom, da sta "kozmična" in "psihična" zvezda v resnici ena in ista zvezda. Razložiti, kako je to mogoče, ne da bi zapadli v precej banalen absolutni solipsizem, pa ne more biti več stvar te razprave. Zadovoljiti se bo treba s preprosto ugotovitvijo, da mistika pač ljubi paradokse.

\section{BIBLIOGRAFIJA}

Viri

Beulay, Robert, izd. La collection des lettres de Jean de Dalyatha. Patrologia orientalis 39. Turnhout: Brepols, 1978. [=Lettres]

Frankenberg, Wilhelm. Euagrius Ponticus. Abhandlungen der Gesellschaft der Wissenschaften zu Göttingen, Philologisch-Historische Klasse 13,2. Berlin: Weidmann, 1912.

Guillaumont, Antoine, izd. Les six centuries des "Kephalaia gnostica" d'Évagre le Pontique [=KG]. Patrologia orientalis 28. Pariz: Firmin-Didot et Cie., 1958.

—_izd. Évagre le Pontique, Traité pratique ou le moine, zv. 1. Sources Chrétiennes 170. Pariz: Cerf.

Gehin, Paul, izd. Évagre le Pontique, Chapitres des disciples d'Évagre. Pariz: Cerf, 2007.

Géhin, Paul, Claire Guillaumont in Antoine Guillaumont, izd. Évagre le Pontique. Sur les pensées. Sources Chrétiennes 438. Pariz: Cerf, 1998.

Harb, Paul, in François Graffin, izd. Joseph Ḥazzāyā. Lettre sur les trois étapes de la vie monastique. Patrologia orientalis 45. Turnhout: Brepols, 1992.

Muyldermans, Joseph. »Evagriana.« Le Muséon 44 (1931): 37-68, 369-83.

21 Homilija 20, nav. po Beulay, Lumière sans forme, 48.

22 Prim. ibid., 72. Danes ga patrologi raje imenujejo Psevdo-Makarij. 
Origen. O počelih. Prevod Neža Sagadin in Gorazd Kocijančič. Ljubljana: KUD Logos, 2013.

\section{Druga Literatura}

Beulay, Robert. La Lumière sans forme: introduction a l'étude de la mystique chrétienne syro-orientale. Chevetogne: Éd. de Chevetogne, 1987.

Bousset, Wilhelm. Apophthegmata: Studien zur Geschichte des ältesten Mönchtums, Tübingen: Mohr, 1923.

Chadwick Owen, John Cassian. Cambridge: Cambridge University Press, 1968.

Colless, Brian E. »The Mysticism of John Saba." Orientalia Christiana Periodica 39 (1973): 83-102.

- The Wisdom of the Pearlers: An Anthology of Syriac Christian Mysticism. Kalamazoo, Mich.: Cistercian Publications, 2008.

Guillaumont, Antoine. Les "Képhalaia gnostica" d'Évagre le Pontique et l'histoire de l'origénisme chez les grecs et chez les syriens. Pariz, 1962.

_. Aux origines du monachisme chretien: pour une phénoménologie du monachisme. Bégrolles en Mauges: Abbaye de Bellefontaine, 1979, 136-147.

—. Un philosophe au désert: Évagre le Pontique. Pariz: Vrin, 2004.

Harmless, William. Desert Christians: An Introduction to the Literature of Early Monasticism. Oxford in New York: Oxford University Press, 2004.

Linge, David E. »Leading the Life of Angels: Ascetic Practice and Reflection in the Writings of Evagrius Pontus«. Journal of the American Academy of Religion 68 (2000): 537-68.

Monaci Castagno, Adele. »Astri.« V: Origene, Dizionario, la cultura, il pensiero, le opere, ur. Adele Monaci Castagno et al., 40-43. Rim: Città Nuova Editrice, 2000.

Scott, Alan. Origen and the Life of the Stars: A History of an Idea. Oxford: Clarendon, 1994.

von Balthasar, H. U. »Metaphysik und Mystik des Evagrius Pontikos.« Zeitschrift für Aszese und Mystik 14 (1939): 31-47. 